\title{
LA POLIITICA EXTERIOR JAPONESA HACIA AMÉRICA LATINA Y EL CARIBE: ENTRE LA COOPERACIÓN Y LOS NEGOCIOS 1
}

\author{
JAPANESE FOREIGN POLICY TOWARDS LATIN AMERICA \\ AND THE CARIBBEAN: BETWEEN COOPERATION AND \\ BUSINESS
}

\section{CÉSAR ROSS ${ }^{2}$}

\section{RESUMEN}

La política exterior de Japón ha sido caracterizada únicamente por sus rasgos más visibles, comercio y cooperación, y desprovista de una dimensión política e ideológica. A mediados de la década del '90 esta visión fue matizada por otra (D. Arase) que aseveraba que la cooperación ocultaba una bien planeada estrategia diplomática dirigida a incrementar la influencia política de Japón a nivel internacional, creándose así una visión alternativa a la llamada doctrina Yoshida. La aplicación de la tesis de David Arase al caso específico de América Latina y el Caribe, permite observar que aquélla, si bien es teóricamente verosímil carece de sustento empírico suficiente para ser considerada totalmente verdadera. En las páginas siguientes exponemos la singularidad de la problemática y las contrapruebas a la tesis de Arase.

Palabras clave: Japón, América Latina, cooperación, negocios, relaciones internacionales.

\section{ABSTRACT}

Japanese foreign policy has typically been characterized by its most visible features, trade and cooperation, while lacking a political and ideological dimension. In the middle of the '90s this vision was qualified through the addition of another dimension

\footnotetext{
${ }^{1}$ Este estudio ha sido financiado por el Fondo Nacional para el Desarrollo Científico y Tecnológico, Fondecyt (Concurso Regular, Proyecto No 1060184).

${ }^{2}$ Académico del Instituto de Estudios Avanzados de la Universidad de Santiago de Chile. Email: cesar.ross@usach.cl.El autor de este trabajo agradece al personal de la Asian Reading Room y del Main Room (Jefferson Building) de la Biblioteca del Congreso de los Estados Unidos, por la atenta colaboración que le prestaron en su pasantía de investigación durante el año 2008.
} 
(D. Arase) which affirmed that cooperation was concealing a well-planned diplomatic strategy to increase Japan's political influence at the international level, thus creating an alternative to what was known as the Yoshida doctrine. The application of David Arase's thesis to the specific case of Latin America and the Caribbean allows us to observe that, while theoretically credible, it lacks sufficient empirical support to be considered entirely true. In the following pages we present the uniqueness of the problem as well as counter-evidence to Arase's thesis.

Keywords: Japan, Latin America, cooperation, business, international relations.

Recibido: 05.08.09. Aceptado: 28.11.11.

\section{INTRODUCCIÓN}

$\mathrm{L}$

AS RELACIONES ENTRE Japón y América Latina y el Caribe han estado caracterizadas por la imagen de un vínculo casi híbrido en lo negocios y en un segundo plano por el enfoque humanitario de la cooperación. Sin embargo, desde mediados de la década del '90 un nuevo enfoque surgió a raíz de la investigación de David Arase, cuya tesis central planteó que bajo el supuesto ascetismo de la cooperación se escondía una estrategia para "comprar poder". Tal afirmación contribuyó poderosamente a transformar las interpretaciones de entonces y abrió una nueva perspectiva para examinar los matices de la política exterior japonesa, que iban mucho más allá de la llamada "doctrina Yoshida".

Este trabajo pretende tanto aplicar la hipótesis general de Arase a las relaciones entre Japón y América Latina y el Caribe, como contrastarla con datos que tienden a contradecir su idea general.

En este artículo se plantea como hipótesis general que las relaciones entre ambas regiones han estado caracterizadas por una combinación entre cooperación y negocios, cuyo detalle impide aseverar ni que haya correlación plena entre los intereses de los negocios con los de la cooperación, ni que sea posible afirmar que la cooperación, como una especie de "soft power" sea restituida con compensaciones económicas.

Así mismo, la inexistencia actual de una base empírica para disprobar la tesis de Arase en el caso de América Latina y el Caribe, no permite afirmar de manera tajante que dichos intereses no existan y no operen en alguna medida. 
Como hipótesis específicas, afirmamos lo siguiente:

Primero, concluida la Segunda Guerra Mundial, el nuevo escenario internacional se estableció mediante negociaciones entre las nuevas "superpotencias", entre los años 1945 y 1947, y que marcaron la ruptura de la llamada "Gran Alianza" entre los Estados Unidos y la Unión Soviética.

En este contexto, Europa, Japón y una parte de América Latina quedaron bajo la influencia hegemónica de los Estados Unidos.

En ese escenario, Shigeru Yoshida, que presidió el gobierno en 1946-47, escogió buscar la nueva razón de ser del país en "el sistema de libre comercio, centrado alrededor de Estados Unidos y Gran Bretaña", donde pretendía hallar el espacio necesario para que Japón fuera nuevamente aceptado en la sociedad internacional (Masataka Kosaka, 2000).

Esta estrategia es conocida como "doctrina Yoshida" y como resultado de ella, "la política exterior del Japón de la post guerra fue restituida a áreas de 'baja política', involucradas con los intereses económicos de Japón. Esto significa que la diplomacia fue a usar los instrumentos económicos para proyectar a Japón a una posición internacional” (Arase, 1995, p. 203)3.

Segundo, Japón está cambiando. Después de años de una conducta internacional prudente y paralizados los debates domésticos sobre política de seguridad, un amplio consenso se está formando para que Japón imponga su interés nacional más poderosamente. Mientras esto no sea una estrategia coherente, ahí hay una emergente visión estratégica -un realismo reticente- que está siendo formado por la combinación de información del cambio externo en el ambiente internacional de Japón, inseguridad acerca de las fuentes del poder nacional y las aspiraciones por la identidad nacional que se mueve más allá del legado de la Segunda Guerra Mundial.

Tercero, desde el punto de vista de la política exterior, la AOD se fue transformando en una fuente de prestigio y legitimidad internacional, tanto por ser una manera de "comprar poder" (Arase, 1995), como por ser una forma de ejercer un tipo muy atractivo de "soft power".

Cuarto, en oposición a lo que sostiene la mayoría de la bibliografía, en relación a que sí existe concentración de la cooperación en aquellos sectores y subsectores económicos donde se concentra el comercio y las inversiones directas, la evidencia empírica no permite sostener que sí exista dicha correlación entre comercio, inversión directa y cooperación.

\footnotetext{
${ }^{3}$ En este razonamiento cabe incluir la tesis de Robert Gilpin, en cuanto a que la guerra hegemónica "es creada como reflejo de la jerarquía de las capacidades de los Estados en cerrar un conflicto” (Gilpin, 1981, pp. 186 y ss.).
} 
Tal contradicción abre un campo para una nueva indagación, más específica: por país, por sector y subsector económico y por proyectos de cooperación específicos.

Desde el punto de vista de la estructura del artículo, éste está compuesto por cuatro partes. Primero, una sección referida al contexto histórico de la política exterior japonesa. Segundo, una caracterización de la política exterior japonesa postguerra fría. Tercero, un acápite referido la relación entre poder y política exterior japonesas, pero remitidos al rol de la cooperación. Y cuarto, un contraste entre los intereses de los negocios y los de la cooperación para el período 1992-2003.

\section{CONTEXTO HISTÓRICO DE LA POLÍTICA EXTERIOR JAPONESA}

\subsection{Política exterior post Segunda Guerra Mundial}

Concluida la Segunda Guerra Mundial, el nuevo escenario internacional se estableció mediante negociaciones entre las nuevas "superpotencias", entre los años 1945 y 1947, y que marcaron la ruptura de la llamada "Gran Alianza” entre los Estados Unidos y la Unión Soviética. En ese último año ya se apreciaba una relación bipolar que el mundo conocería como "Guerra Fría" (Powaski, 1998), en la que cada una de estas superpotencias se convertía en el eje de su propia área de influencia ${ }^{4}$.

En este contexto, Europa, Japón y una parte de América Latina quedaron bajo la influencia hegemónica de Estados Unidos.

En el escenario de guerra y postguerra, los Estados Unidos procuró garantizar la lealtad militar y política de América Latina y Japón. En el primer caso, mediante la institucionalización de nuevas instancias, como fueron el TIAR, Tratado de Interamericanos de Asistencia Recíproca (1947) y la OEA, Organización de Estados Americanos (1948), y en el segundo caso, con la suscripción de un convenio de seguridad mutua en 1952, donde este país ofreció bases militares a las fuerzas norteamericanas y dinero para amortizar los gastos de las tropas estadounidenses (Kikuchi, 1993: 125).

\footnotetext{
${ }^{4}$ El término "guerra fría" fue por primera vez utilizado por el escritor español Don Juan Manuel en el siglo XIV. En su acepción moderna fue reutilizado por Bernard Baruch, consejero del Presidente Roosevelt, quien usó el término en un debate en 1947 y fue popularizado por el editorialista Walter Lippmann.
} 


\subsection{Condición pacífica de Japón y noción de "soft power"}

Paralelamente, Japón fue sometido a un proceso de reorganización inducido por los Estados Unidos, mediante la figura de un interventor que recibió la denominación de Gobernador, en la figura del general Douglas W. MacArthur, quien escribió la rendición japonesa a bordo del acorazado Missouri, el 2 de septiembre de 1945, e implementó las transformaciones ulteriores del país.

Uno de los aspectos clave de esta reorganización fue la nueva Constitución Política ${ }^{5}$, que establecía que el Emperador perdía su carácter de ser supremo, inviolable y sagrado, y quedaba reducido a un símbolo, y que depositaba el poder soberano en el pueblo.

Además, se creó una Asamblea que poseía el poder de legislar; se abolió la aristocracia feudal; y se garantizaron las libertades populares, pero la norma más innovadora fue la contemplada en el artículo 9 (Capítulo II), donde se señaló que el pueblo japonés renunciaba para siempre a la guerra como derecho soberano de la nación y a la amenaza o al uso de la fuerza como medio de resolver conflictos internacionales.

Rápida y dramáticamente, Japón perdió su condición de país guerrero, rasgo que tanto se había exacerbado a contar de la Guerra Ruso-Japonesa (Makoto Iokibe, 2000).

En ese escenario, Shigeru Yoshida, que presidió el gobierno en 1946-47, escogió buscar la nueva razón de ser del país en "el sistema de libre comercio, centrado alrededor de Estados Unidos y Gran Bretaña", donde pretendía hallar el espacio necesario para que Japón fuera nuevamente aceptado en la sociedad internacional (Masataka Kosaka, 2000).

Esta estrategia es conocida como "doctrina Yoshida" y como resultado de ella, "la política exterior del Japón de la post guerra fue restituida a áreas de 'baja política', involucradas con los intereses económicos de Japón. Esto significa que la diplomacia fue a usar los instrumentos económicos para proyectar a Japón a una posición internacional" (Arase, 1995, p. 203) ${ }^{6}$.

En la sucesión de períodos de paz, como señala Robert Gilpin, las diferencias en las tasas de crecimiento económico que registran los países cambian la posición relativa de los estados en el ranking de la jerarquía de sus capacidades, pero el de la "jerarquía política” permanece estático.

\footnotetext{
${ }^{5}$ Promulgada el 3/11/1946 y cuya entrada en vigor fue el 3/5/1947.

${ }^{6}$ En este razonamiento cabe incluir la tesis de Robert Gilpin, en cuanto a que la guerra hegemónica "es creada como reflejo de la jerarquía de las capacidades de los Estados en cerrar un conflicto” (Gilpin, 1981, p. 186 y ss.).
} 
Esta des-sincronización o diacronía produce tensiones internacionales, como la subida de estados en materia de poder económico, los que a su vez quieren ver reflejado este mejor ranking en el terreno político. En consecuencia, la guerra hegemónica es esperable cuando un Estado gana una capacidad creíble para desafiar a aquel que ocupa el rol predominante en la jerarquía política internacional.

En este sentido, y siguiendo el razonamiento de Gilpin, es interesante observar que la transformación, asociada a la Doctrina Yoshida también puede ser interpretada desde otro punto de vista: la Segunda Guerra Mundial no cambió sustancialmente la orientación del Estado japonés moderno, sino que sólo fue un cambio de estrategia, ya que desde el período Meiji Japón se orientó a la búsqueda del mejoramiento de su posición en un sistema internacional dominado por Occidente, y lo mismo puede ser dicho del estado japonés de la postguerra.

La doctrina del Primer Ministro Shigeru Yoshida fue concentrar a Japón en los asuntos económicos y dejar la seguridad en manos de los Estados Unidos, ya que de esta manera recuperarían su jerarquía económica mundial más rápido. En palabras del mismo Yoshida, "llegará el día cuando recobremos nuestro sustento. Esto puede sonar maquiavélico, pero dejemos en las manos de los americanos [nuestra seguridad] hasta entonces" (Pyle, 1992, p. 26).

En este contexto, donde a Japón le fue negado el denominado "hard power", el país se refugió en el "soft power", donde la cooperación internacional, especialmente aquélla destinada al desarrollo, se transformó en el principal instrumento.

\section{POLÍTICA EXTERIOR JAPONESA POST GUERRA FRÍA}

El debate acerca de la política exterior de Japón en la post Guerra Fría exhibe un cierto consenso en cuanto a los aspectos sustantivos de la transición que ha descrito desde 1991 en adelante. Entre varios autores ${ }^{7}$, se ha elegido usar la caracterización realizada por Michael J. Green (2003), cuya sistematización refleja suficientemente los aspectos de continuidad y de cambio contenidos por aquel debate.

\footnotetext{
${ }^{7}$ Entre otros, ver a: Fukushima (1999, Hagström (2003), Hook et al. (2001), Ikenberry (2003), Togo (2005).
} 
Según el autor, existe una fuerte continuidad en los parámetros de la política exterior de Japón desde el final de la Guerra Fría, al menos en cuatro aspectos sustantivos: la centralidad de los Estados Unidos, la primacía de las herramientas económicas, la restricción en el uso de la fuerza, e inexistencia de alternativa a la visión estratégica.

Centralidad de los Estados Unidos: Se sostiene que la política exterior japonesa continúa tomando sus influencias desde Washington, en el ínterin en que puede incrementar su independencia de los márgenes (particularmente en el sudeste de Asia). Una cuestión fundamental para los intereses de los Estados Unidos es que Japón conserve su deferencia y prudencia. En términos de seguridad, hay un amplio consenso en la necesidad de la alianza EE.UU.-Japón ante cualquier otro punto en la historia japonesa de postguerra, aunque hay más desacuerdo en las cuestiones específicas, como las bases de EE.UU., Japón mantiene una dependencia de la hegemonía americana respecto de su propia seguridad en el este de Asia.

Ciertamente, mucha de la diplomacia japonesa está apuntada al contrafuerte que constituye el liderazgo de los Estados Unidos en Naciones Unidas y en las instituciones financieras internacionales.

Primacía de las herramientas económicas: Se postula que, a pesar del incremento en la concentración en la preocupación de la seguridad tradicional y un reconocimiento del declive relativo de los recursos económicos, la política exterior de Japón continúa comerciando con herramientas económicas para el poder e influencia. Estas herramientas incluyen ayuda externa [cooperación] y contribuciones a organizaciones internacionales, así como colocación de inversión extranjera directa. En respuesta a la política regional y crisis de seguridad de los 90, la primera respuesta de Japón ha sido financiera.

En cuanto a la restricción en el uso de la fuerza, se establece que la restricción normativa e institucional en el uso de la fuerza permanece fuerte, aunque más flexible. Nuevas misiones y capacidades para la construcción de la paz, operaciones no combatientes para evacuación, vigilancia de espacio, y apoyo logístico para las fuerzas de los Estados Unidos en contingencias regionales, todo lo cual da a Japón más herramientas para su propia experiencia en seguridad.

Inexistencia de una alternativa a la visión estratégica: Se plantea que el no ser un líder político ha articulado una clara alternativa para la actual doctrina 
de la política exterior japonesa. Los líderes políticos han anunciado nuevas iniciativas hacia Rusia o el sudeste de Asia, pero no es un mandato político audaz para la reformulación del rol de Japón en el mundo. En parte esto es un reflejo de la debilidad del liderazgo "senior" actual en los partidos políticos japoneses, pero también está basado en el conservadurismo del público japonés respecto de los asuntos internacionales y una desconfianza en la demagogia.

Por otra parte, también se identifica y caracteriza a lo menos seis cambios relevantes en la política exterior pos Guerra Fría, que representan nuevas ideas y nuevos patrones de diplomacia desde el final de la Guerra Fría, que reflejan un pronunciado despegue del pasado.

Una gran concentración en el balance del poder: La política exterior de Japón ha estado siendo formada crecientemente por consideraciones estratégicas, respecto del balance del poder e influencia en el noreste de Asia, particularmente vis-a-vis con China. En el pasado las relaciones de Japón en el este de Asia eran primariamente determinadas por la conjunción de intereses mercantiles, así como estratégicos para los Estados Unidos. Ahora, ellos tienden también a reflejar una autoconciencia de la competencia con China por la influencia estratégica en la región.

Realismo creciente, idealismo contenido: Con este realismo creciente acerca de las relaciones de poder en la región y la amenaza de la disminución por los recursos económicos domésticos, en Japón se ha perdido espacio para sentimentalismos, idealismo, o culpa en su política exterior en Asia, donde el debate japonés sobre un rol mundial en los 80 fue enmarcado en términos de la "obligación internacional" (kokusai koken) u "obligación" (giri) de la nación acreedora del mundo por más tiempo. Hoy la política exterior debe estar justificada ante el público en términos de "interés nacional" (kokueki).

Una alta sensibilidad a la seguridad: La clase política japonesa es más sensible a la seguridad por amenaza externa que aun durante el momento más alto de la Guerra Fría. Esto queda reflejado por el trauma externo producido por: las pruebas nucleares chinas de 1995, la crisis por el estrecho de Taiwán, por el lanzamiento de los misiles Taepodong de Corea del Norte en 1998, así como también por la incertidumbre del futuro económico de Japón.

Con el colapso de la antigua izquierda socialista y la emergencia de una 
nueva generación de líderes políticos desafectada por las culpas de la guerra, hay un ambiente más permisivo para avanzar en la agenda de la seguridad nacional.

Un más determinado empuje para una política exterior "independiente": Japón está promoviendo fuerte para una identidad diplomática más independiente en el mundo. Esto es un reflejo de la confianza de una nueva generación de políticos en asuntos internacionales, así como de la búsqueda de propósitos nacionales e identidad después de la desaparición del modelo económico japonés. Esto también se refleja en que se ha incrementado en la gente japonesa el sentimiento por la integridad del Estado-nación.

Concentración en Asia: Para extender la política exterior japonesa, ha desarrollado características independientes, lo que ha hecho destacar las diferencias entre Washington y las naciones del este de Asia. Las divergencias japonesas con los Estados Unidos sobre Burma y Camboya en los 1990 reflejada en la Association of Southeast Asian Nations (ASEAN), demuestra la preocupación de Washington por enfatizar los derechos humanos a expensas de la estabilidad regional. Similarmente, las iniciativas japonesas en respuesta a la crisis financiera de 1997, reflejan la alarma asiática ante la inestabilidad del Fondo Monetario Internacional a las condiciones regionales y la estabilidad política.

Un proceso más fluido de construcción de la política exterior: El estado de transición de la política japonesa doméstica, más que agregar claridad ha hecho más compleja la construcción de la política exterior. Las instituciones dominantes del gobierno japonés -el PLD, las facciones, la burocracia- están aún a cargo, pero ellos se están volviendo más frágiles, menos cohesionados y menos jerárquicos. En el intertanto, las limitaciones de la coalición gobernante y la presión de los desafíos de la reestructuración de la economía doméstica ha impedido una atención prolongada hacia la política internacional por parte de los líderes políticos mayores.

En breve, Japón está cambiando. Después de años de una conducta internacional prudente y paralizados debates domésticos sobre política de seguridad, un amplio consenso se está formando para que Japón imponga su interés nacional más poderosamente. Mientras esto no sea una estrategia coherente, ahí hay una emergente visión estratégica -un realismo reticente- que está siendo formado por la combinación de información del cambio externo en el ambiente internacional de Japón, inseguridad acerca de 
las fuentes del poder nacional y las aspiraciones por la identidad nacional que se mueve más allá del legado de la Segunda Guerra Mundial.

\section{PODER Y POLÍTICA EXTERIOR: ROL DE LA COOPERACIÓN}

\subsection{Poder y política exterior}

En abstracto, el poder viene a ser la capacidad de un sujeto o sujetos organizados para conseguir que otro u otros hagan su voluntad.

Pero el poder también es un fenómeno relacional, con dependencia al lugar que se ocupe en una estructura mayor (con grados variables de acumulación), con arreglo a las relaciones político-económicas que definan a ésta y con sujeción a las reglas (instituciones) ${ }^{8}$ y organizaciones dominantes en un momento histórico determinado.

Utilizando la taxonomía de John Galbraith, se podría asegurar que esta asimetría se concretó a través de tres formas: el poder condigno, el poder compensatorio y el poder condicionado (Galbraith, 1985, cap. II y III). El primero se refiere al uso de la sanción para imponer una decisión, el segundo a la compensación o premio y el tercero apunta a la definición de comportamientos condicionados a ciertos intereses de manera inconsciente. A esta taxonomía podría agregarse la noción que Joseph Nye Jr. acuñó en oposición a la tradicional de "hard power", como fue la de "soft power" (2004).

Desde el punto de vista de las relaciones internacionales, la idea del poder ha cruzado todo el debate de las llamadas escuelas o perspectivas realista y neorrealista. En ellas, el poder es la categoría central, cuya significación ha variado de acuerdo a cómo el contexto internacional, y la teorización derivada de él, ha sufrido transformaciones de relevancia.

Para el "realismo", el objetivo principal de la política internacional es maximizar dividendos en seguridad, siendo éste el valor central al que cada país debe aspirar'. En pro de su consecución, el Estado debe utilizar todos sus recursos de poder. Para los años de la Guerra Fría (1947-91), domina-

\footnotetext{
${ }^{8}$ Uso el término "institución” como sinónimo de "regla”, asumiendo como válida para este análisis la definición que hizo Douglass C. North sobre estos conceptos. Ver: "Institutions, Institutional Change and Economic Performance" (cap. 1), Cambridge University Press, New YorkUnited States, 1990.

${ }^{9} \mathrm{El}$ autor que forjó esta mirada fue Hans Morgenthau, con su libro Política entre naciones. La lucha por el poder y la paz, publicado por primera vez en 1948.
} 
da por la visión realista, la principal expresión de éste fue el ejercicio del llamado "poder duro", "hard power", o también llamado "condign power" (Galbraith, 1985).

Para el "neo-realismo", el objetivo central de la política internacional es maximizar en dividendos económicos, también como central al que cada país debe aspirar. Detrás de este propósito, Estado y mercado transformaron la relación que históricamente había estado dominada por el conflicto, por otra marcada por la cooperación. Este nuevo trato caracterizó la relación Estado-mercado a contar de 1991, en un proceso que para Japón se había iniciado con la post Guerra Fría, bajo la llamada "doctrina Yoshida".

\subsection{El rol de la cooperación}

La política de cooperación internacional de Japón comenzó en 1954, y para 1989 ya era el primer donante en el mundo en Ayuda Oficial al Desarrollo (AOD).

La AOD japonesa fue muy valiosa para el desarrollo social-económico, y un importante factor en el fenómeno de las relaciones amistosas entre Japón y los receptores. Esto ha sido particularmente cierto respecto de los países asiáticos vecinos, que han recibido la mayor cantidad de ayuda japonesa, pero también para otros, en los que Japón fue la fuente más caudalosa de ayuda extranjera (treinta y uno en 1991 y veintiocho en 1992).

De este modo, al incrementar la AOD, Japón no sólo coopera con la comunidad internacional fomentando la estabilidad, el desarrollo, la democratización y las reformas para implantar la economía de mercado en los países receptores, sino que también establece relaciones bilaterales más estrechas y fortalece la mutua comprensión en los campos políticos y económicos (Hirabayashi, 1995, pp. 19-20).

Desde el punto de vista de la política exterior, la AOD se fue transformando en una fuente de prestigio y legitimidad internacional, tanto por ser una manera de "comprar poder" (Arase, 1995), como por ser una forma de ejercer un tipo muy atractivo de "soft power". Por consiguiente, el programa de AOD es uno de los instrumentos más importantes de la diplomacia japonesa, y en virtud de eso, algunos creen que este país debería asumir un liderazgo activo en este campo, en la medida que existe una relación directamente proporcional entre el volumen de la ayuda, el volumen del liderazgo y el tamaño del poder internacional (Hirabayashi, 1995).

En síntesis, Japón ha renunciado a la guerra y a la posesión de armas nucleares y ha basado su desarrollo en la adquisición de los recursos para sa- 
tisfacer sus necesidades mediante el comercio, la inversión y la exportación de productos manufacturados y servicios. Por consiguiente, la seguridad y la prosperidad de Japón dependen de la paz y la estabilidad de la comunidad internacional y de una economía mundial abierta y libre. Gracias a las contribuciones pacíficas de Japón a los países en vías de desarrollo, mediante ayuda financiera y técnica, crece sin cesar el número de personas y de países de todo el mundo que se consideran sus amigos. Por lo tanto, la AOD sirve a Japón para conseguir un "puesto de honor" en el seno de la sociedad internacional, tal como se postula en el preámbulo de su Constitución Política (Hirabayashi, 1995, p. 20), así como le sirve para posicionarse en la estructura del poder mundial, tal y como lo planteó David Arase en 1995.

En esta doble condición, la cooperación internacional de Japón es tanto un modo de concebir su lugar en el mundo, como su forma de insertarse internacionalmente, mediante una estrategia de "soft power" (Joseph S. Nye Jr., 2004), vale decir, sin el recurso del poder político y geoestratégico, pero con el efectivo poder derivado de la jerarquía económica.

\subsection{Política japonesa de cooperación hacia América Latina}

Los autores que más han trabajado este tema ${ }^{10}$ coinciden en sus puntos de vista respecto de 4 aspectos centrales:

Rol secundario de América Latina: Con una inclinación estadística evidente, la cooperación japonesa se ha concentrado en Asia, con un promedio de 68,1\% del total de la AOD, para el período 1975-1990.

En este contexto, y para el mismo período, las otras regiones obtuvieron fondos de magnitudes muy menores: Medio Oriente 9,8\%; África 9,9 y América Latina 7,1\%.

Esta última región, al igual que África, vio que la AOD japonesa se incrementaba notoriamente.

Tendencia general de la cooperación: Como señala el profesor Horisaka, desde mediados de la década de los ochenta el Gobierno japonés realizó importantes esfuerzos para ampliar considerablemente la cooperación económica con los países en vías de desarrollo. Es así como en la década de 1980

\footnotetext{
${ }^{10}$ Aunque para el período inmediatamente anterior al que interesa a esta investigación (Horisaka, 1994 y Hosono, 1995).
} 
se percibe un aumento notable del porcentaje de la AOD destinado a los países latinoamericanos. Si bien en 1975 era el 5,6\% de la AOD, ya en 1991 (al final de la segunda etapa) había superado el 9,6\%.

Estructura de la AOD japonesa hacia América Latina: Se ha estructurado en función del nivel de renta de los países. En lo que se refiere a los países con una renta per cápita superior, Japón colabora mediante la concesión de préstamos en yenes. A los países con una renta per cápita media-alta, como México, Argentina [hasta comienzos de la década de 1990] y Brasil, se tiende a prestar ayuda en forma de préstamos en yenes y de colaboración técnica, sobre todo en el campo de medio ambiente. Los países con una renta per cápita baja, como son los países centroamericanos y Bolivia, obtienen una alta proporción de las ayudas en forma de donación de fondos y de ayuda técnica.

Reducción de la deuda y realización de ajustes estructurales: Desde mediados de la década de los ochenta se observó un incremento de la cooperación japonesa con los países que poseían una deuda importante. Entre ellos, fundamentalmente México y Brasil. Japón colaboró con este problema fuera de la AOD y en el marco del llamado Plan Brady, donde contribuyó con varios países, como México (1.900 millones de dólares), Venezuela (600 millones de dólares) y Argentina (900 millones de dólares).

En 1988 financió el segundo programa de ajuste estructural de Costa Rica, mediante fondos de AOD en consorcio con el Banco Mundial, por un total de 100 millones de dólares.

Japón desempeñó, a nivel general, una función crucial en momentos en que los países latinoamericanos tenían dificultades para obtener financiamiento en el extranjero a causa de la crisis originada por acumulación de deudas, a partir de 1982.

El Banco de Exportación-Importación de Japón aportó a la asistencia a México, por ejemplo, con un total de 7.000 millones de dólares en la década de los ochenta.

Cabe señalar que una buena parte del presupuesto que figuraba en el Programa de Reciclaje de Fondos de Japón, se destinó a la cooperación directa o indirecta con los países latinoamericanos.

Hasta marzo de 1992 esta cooperación ascendió a 4.178.800 millones de yenes. De esta suma se destinaron 1.223.100 millones a los países latinoa- 
mericanos y 477.100 millones a la contribución a los organismos financieros internacionales.

\subsection{Cooperación japonesa hacia América Latina en cifras}

Para el caso detallado de esta región se ha tomado a todos los países de América Latina que recibieron cooperación en el período 1992-2003 (20 en total), a fin de diferenciar el perfil de las subregiones y sectores de intervención, así como la naturaleza de dicha ayuda, a fin de establecer la existencia de ciertos patrones generales.

\subsubsection{Cooperación japonesa hacia América Latina en cifras: países}

La primera observación que se desprende de la tabla siguiente tiene que ver con el foco subregional de la cooperación japonesa. La mayor parte de ésta ha sido dirigida a Centroamérica y el Caribe y hacia América del Sur.

Tabla 1. América Latina y el Caribe: Cooperación japonesa (No de proyectos ejecutados por sub-región continental).

\begin{tabular}{|l|c|c|c|c|c|c|c|}
\hline Subregión & 1992 & 1993 & 1994 & 1995 & 1996 & 1997 & 1998 \\
\hline América del Norte & 4 & 4 & 3 & 8 & 3 & 4 & 7 \\
\hline Centroamérica y el Caribe & 15 & 23 & 28 & 18 & 16 & 22 & 21 \\
\hline América del Sur & 14 & 16 & 15 & 33 & 10 & 13 & 25 \\
\hline Total & 33 & 43 & 46 & 59 & 29 & 39 & 53 \\
\hline Subregión & 1999 & 2000 & 2001 & 2002 & 2003 & Total & $(\%)$ \\
\hline América del Norte & 2 & 1 & 2 & 1 & 2 & 41 & 8,65 \\
\hline Centroamérica y el Caribe & 16 & 16 & 12 & 17 & 3 & 223 & 47,05 \\
\hline América del Sur & 15 & 16 & 23 & 8 & 22 & 210 & 44,30 \\
\hline Total & 33 & 33 & 37 & 26 & 27 & 474 & 100,00 \\
\hline
\end{tabular}

Fuente: Elaboración propia, sobre la base de información oficial de las páginas web de JICA en cada país indicado.

Nota: La columna de totales ha sido complementada con los datos de El Salvador, país que sólo exhibe las cifras totales (no desagregadas por año) del período 1992-2003. Por esta razón, la fila de totales por año es diferente a la tabla por subregiones.

América del Norte, que para efectos de nuestro análisis queda reducida a México, muestra una participación superior al promedio de toda la 
región ${ }^{11}$, alcanzando a 41 proyectos, lo que equivale a 8,65 del total. Estas cifras se explican porque los extremos de la muestra son 83 y 1 proyecto, correspondientes a Honduras y Ecuador, respectivamente. Adicionalmente, esto se explica por la alta relevancia que México tiene para Japón dentro del contexto de su vecindad con los Estados Unidos, así como por su pertenencia a NAFTA, todo lo cual lo hace un socio estratégico y relevante dentro de la región.

Dentro de la subregión de Centro América y el Caribe, con 10 países involucrados, es posible advertir que la mayor proporción de la cooperación japonesa ha sido captada por Centroamérica, con un $87 \%$ de total, en tanto el Caribe ha captado sólo el 13,0\%.

Como puede apreciarse en la tabla siguiente, dentro del Caribe sólo 3 países han recibido esta ayuda, siendo República Dominicana el más relevante entre ellos.

Por su parte, dentro de los estados agrupados en Centroamérica, Honduras es el país que ha recibido más proyectos, con un total de $83(37,2 \%)$, seguido por Guatemala con $39(17,4 \%)$ y por Nicaragua con $34(15,2 \%)$.

Tabla 2. Centroamérica y el Caribe: Cooperación japonesa (№ de proyectos ejecutados por país).

\begin{tabular}{|l|r|r|r|r|r|r|r|}
\hline País & 1992 & 1994 & 1997 & 2000 & 2003 & Total & $(\%)$ \\
\hline Costa Rica & $\mathrm{s} / \mathrm{i}$ & $\mathrm{s} / \mathrm{i}$ & $\mathrm{s} / \mathrm{i}$ & $\mathrm{s} / \mathrm{i}$ & $\mathrm{s} / \mathrm{i}$ & 5 & 2,24 \\
\hline Cuba & $\mathrm{s} / \mathrm{i}$ & $\mathrm{s} / \mathrm{i}$ & $\mathrm{s} / \mathrm{i}$ & $\mathrm{s} / \mathrm{i}$ & $\mathrm{s} / \mathrm{i}$ & 5 & 2,24 \\
\hline El Salvador & $\mathrm{s} / \mathrm{i}$ & $\mathrm{s} / \mathrm{i}$ & $\mathrm{s} / \mathrm{i}$ & $\mathrm{s} / \mathrm{i}$ & $\mathrm{s} / \mathrm{i}$ & 16 & 7,17 \\
\hline Guatemala & $\mathrm{s} / \mathrm{i}$ & 12 & 6 & 3 & 1 & 39 & 17,49 \\
\hline Honduras & 10 & 12 & 9 & $\mathrm{~s} / \mathrm{i}$ & $\mathrm{s} / \mathrm{i}$ & 83 & 37,22 \\
\hline Jamaica & $\mathrm{s} / \mathrm{i}$ & $\mathrm{s} / \mathrm{i}$ & $\mathrm{s} / \mathrm{i}$ & $\mathrm{s} / \mathrm{i}$ & $\mathrm{s} / \mathrm{i}$ & 3 & 1,35 \\
\hline Nicaragua & 2 & 1 & 1 & 9 & $\mathrm{~s} / \mathrm{i}$ & 34 & 15,25 \\
\hline Panamá & 1 & 3 & 4 & 2 & $\mathrm{~s} / \mathrm{i}$ & 17 & 7,62 \\
\hline Rep. Dominicana & 2 & $\mathrm{~s} / \mathrm{i}$ & 2 & 2 & 2 & 21 & 9,42 \\
\hline Total & 15 & 28 & 22 & 16 & 3 & 223 & 100,00 \\
\hline
\end{tabular}

Fuente: Elaboración propia, sobre la base de información oficial de las páginas web de JICA en cada país indicado.

Notas: a) La columna de totales ha sido complementada con los datos de El Salvador, país que sólo exhibe las cifras totales (no desagregadas por año) del período 1992-2003. Por esta razón, la fila de totales por año es diferente a la tabla por subregiones; b) La serie completa puede verse en Ross (2008), "La cooperación japonesa hacia América Latina, 1992-2003”, en Política y Estrategia, № 110 (abril-junio), Academia Nacional de Estudios Políticos y Estratégicos (ANEPE), Santiago-Chile, pp. 108-136.

\footnotetext{
${ }^{11}$ Sólo 2,7\% (13 proyectos) del total.
} 
Para el caso de América del Sur, observamos que 10 países han obtenido cooperación japonesa en proporciones muy variadas. Perú con 58 proyectos $(27,6 \%)$, seguido por Argentina con 39 proyectos $(18,5 \%)$ y por Bolivia con $21(10,0 \%)$.

Tabla 3. América del Sur: Cooperación japonesa (№ de proyectos ejecutados por país).

\begin{tabular}{|l|r|r|r|r|r|r|r|}
\hline País & 1992 & 1994 & 1997 & 2000 & 2003 & Total & $(\%)$ \\
\hline Argentina & 4 & 6 & 2 & 1 & 2 & 39 & 18,57 \\
\hline Bolivia & $\mathrm{s} / \mathrm{i}$ & 1 & $\mathrm{~s} / \mathrm{i}$ & 4 & 3 & 21 & 10,00 \\
\hline Brasil & $\mathrm{s} / \mathrm{i}$ & $\mathrm{s} / \mathrm{i}$ & $\mathrm{s} / \mathrm{i}$ & $\mathrm{s} / \mathrm{i}$ & 4 & 10 & 4,76 \\
\hline Chile & $\mathrm{s} / \mathrm{i}$ & $\mathrm{s} / \mathrm{i}$ & 1 & 4 & 1 & 14 & 6,67 \\
\hline Colombia & 1 & 2 & $\mathrm{~s} / \mathrm{i}$ & $\mathrm{s} / \mathrm{i}$ & 1 & 10 & 4,76 \\
\hline Ecuador & $\mathrm{s} / \mathrm{i}$ & $\mathrm{s} / \mathrm{i}$ & $\mathrm{s} / \mathrm{i}$ & $\mathrm{s} / \mathrm{i}$ & $\mathrm{s} / \mathrm{i}$ & 1 & 0,48 \\
\hline Paraguay & 2 & 4 & 3 & 1 & 1 & 19 & 9,05 \\
\hline Perú & 6 & 1 & 6 & 3 & 1 & 58 & 27,62 \\
\hline Uruguay & $\mathrm{s} / \mathrm{i}$ & $\mathrm{s} / \mathrm{i}$ & $\mathrm{s} / \mathrm{i}$ & 1 & 1 & 12 & 5,71 \\
\hline Venezuela & 1 & 1 & 1 & 2 & 8 & 26 & 12,38 \\
\hline Total & 14 & 15 & 13 & 16 & 22 & 210 & 100,00 \\
\hline
\end{tabular}

Fuente: Elaboración propia, sobre la base de información oficial de las páginas web de JICA en cada país indicado.

Notas: a) La columna de totales ha sido complementada con los datos de El Salvador, país que sólo exhibe las cifras totales (no desagregadas por año) del período 1992-2003. Por esta razón, la fila de totales por año es diferente a la tabla por subregiones; b) La serie completa puede verse en Ross (2008).

Si se considera como criterio el promedio de los proyectos asignados para toda la subregión (21), se podrá apreciar que sólo 4 países lo superan (Argentina, Bolivia, Perú y Venezuela). Del mismo modo, si estimamos la media $(29,5)$ como medida veremos que sólo 2 de ellos superan tal nivel (Argentina y Perú).

¿Qué explica esta concentración? Para el caso del Perú esto es atribuible al peso de la inmigración nipona a ese país y la consideración que ese dato tiene en la política exterior japonesa.

Para el caso de Argentina, las razones son un poco más difusas en un análisis agregado, dado el bajo peso de las relaciones económicas bilaterales, factor que vinculado con el de la cooperación siempre adquiere una alta correlación. En este caso, sin embargo, resulta paradojal la baja consistencia de estos datos. Con todo, existen 3 factores que siempre pueden contribuir a elevar el estándar de Argentina en la cooperación japonesa: a) el poten- 
cial de crecimiento del comercio bilateral, aún muy bajo para las opciones de complementación de ambas economías; b) la cantidad y calidad de los recursos naturales argentinos, cuya riqueza puede ser altamente apetecida por el mercado y la industria nipona; y c) el rol que ha jugado la Fundación Okita en posicionar a Japón y al Asia en general dentro de la agenda argentina. Esta institución es relevante y no tiene equivalentes del mismo nivel en los otros países, incluso en Brasil, donde el peso de la inmigración japonesa ha sido notable.

\subsubsection{Cooperación japonesa hacia América Latina en cifras: sectores de aplicación}

Desde el punto de vista de los sectores de aplicación, y contrariamente a la apreciación general acerca del excesivo pragmatismo japonés, es interesante observar que el número de proyectos con fines humanitarios es equivalente al destinado a reforzar actividades productivas. Esto, que debe ser matizado con los montos de capital asociados, permite replantearse con una mirada más amplia el verdadero significado de la cooperación japonesa dentro de la región.

Tabla 4. América Latina y el Caribe: Cooperación japonesa (No de proyectos ejecutados por sector).

\begin{tabular}{|l|r|r|r|r|r|r|r|}
\hline $\begin{array}{l}\text { Proyectos } \\
\text { (Categorías) }\end{array}$ & 1992 & 1994 & 1997 & 2000 & 2003 & Total & (\%) \\
\hline Productiva & 16 & 28 & 21 & 13 & 8 & 231 & 48,53 \\
\hline Humanitaria & 17 & 18 & 18 & 20 & 19 & 226 & 47,48 \\
\hline Otros & 0 & 3 & 4 & 1 & 0 & 19 & 3,99 \\
\hline Total & 33 & 49 & 43 & 34 & 27 & 476 & 100,00 \\
\hline
\end{tabular}

Fuente: Elaboración propia, sobre la base de información oficial de las páginas web de JICA en cada país indicado.

Notas: a) La columna de totales ha sido complementada con los datos de El Salvador, país que sólo exhibe las cifras totales (no desagregadas por año) del período 1992-2003. Por esta razón, la fila de totales por año es diferente a la tabla por subregiones; b) La serie completa puede verse en Ross (2008).

En el ámbito de la cooperación productiva, asociada al comercio e inversiones japonesas en la región, es posible colegir algunas cuestiones relevantes aunque previsibles. Primero, que América Latina sigue manteniendo una relación de asimetría complementaria con Japón, donde ésta opera como abastecedora de recursos naturales, mientras que el país oriental ofi- 
cia de proveedor de bienes manufacturados. Segundo, y en el área de recursos naturales, encontramos concentrado más del $47 \%$ (110 proyectos), de la cooperación productiva, donde se destaca la agricultura con un $20,6 \%$, la pesca con más de un $9,0 \%$ y la minería con poco más de un 7,0\%. El sector industrial, en la mayoría de los casos complementario a los sectores primarios -especialmente los recién citados-, concentra un nivel levemente superior al 12\% de los proyectos, lo que refuerza la hipótesis planteada más arriba.

Como sectores complementarios se encuentra la cooperación asociada a dar certeza a los negocios, como son: la elaboración de información confiable mediante estudios sobre desarrollo económico (6,4\%); profundización de la institucionalidad democrática, como proyectos de apoyo a los gobiernos (12,0\%); y, desarrollo de obras públicas $(7,7 \%)$, especialmente en aquellos países de desarrollo económico y social más precario.

Tabla 5. América Latina y el Caribe: Cooperación productiva de Japón (No de proyectos ejecutados por sector).

\begin{tabular}{|l|r|r|r|r|r|r|r|}
\hline Proyectos (Categorías) & 1992 & 1994 & 1997 & 2000 & 2003 & Total & $(\%)$ \\
\hline Acuicultura & 0 & 0 & 1 & 0 & 0 & 1 & 0,43 \\
\hline Agricultura & 1 & 12 & 5 & 1 & 5 & 47 & 20,35 \\
\hline Agropecuario & 0 & 0 & 1 & 1 & 0 & 6 & 2,60 \\
\hline Desarrollo econ. & 1 & 1 & 2 & 1 & 0 & 15 & 6,49 \\
\hline Desarrollo rural & 0 & 2 & 0 & 0 & 0 & 2 & 0,87 \\
\hline Economía & 0 & 1 & 4 & 0 & 0 & 7 & 3,03 \\
\hline Expertos & 1 & 1 & 1 & 0 & 0 & 8 & 3,46 \\
\hline Forestal & 0 & 0 & 0 & 1 & 0 & 7 & 3,03 \\
\hline Ganadería & 0 & 2 & 0 & 0 & 0 & 8 & 3,46 \\
\hline Gobierno & 2 & 2 & 2 & 3 & 3 & 28 & 12,12 \\
\hline Hidroeléctrica & 2 & 0 & 1 & 0 & 0 & 4 & 1,73 \\
\hline Industria & 1 & 1 & 1 & 0 & 0 & 28 & 12,12 \\
\hline Minería & 2 & 2 & 1 & 1 & 0 & 17 & 7,36 \\
\hline Misión de estudios & 1 & 1 & 1 & 0 & 0 & 8 & 3,46 \\
\hline Obras Públicas & 2 & 0 & 0 & 4 & 0 & 18 & 7,79 \\
\hline Pesca & 2 & 1 & 0 & 0 & 0 & 21 & 9,09 \\
\hline Telecomunicaciones & 1 & 1 & 0 & 0 & 0 & 2 & 0,87 \\
\hline Transporte & 0 & 1 & 1 & 1 & 0 & 4 & 1,73 \\
\hline Total & 16 & 28 & 21 & 13 & 8 & 231 & 100,00 \\
\hline
\end{tabular}

Fuente: Elaboración propia, sobre la base de información oficial de las páginas web de JICA en cada país indicado

Notas: a) La columna de totales ha sido complementada con los datos de El Salvador, país que sólo exhibe las cifras totales (no desagregadas por año) del período 1992-2003. Por esta razón, la fila de totales por año es diferente a la tabla por subregiones; b) La serie completa puede verse en Ross (2008). 
En el ámbito de la cooperación humanitaria, es posible identificar 17 áreas de trabajo, dentro de las cuales 4 parecen haber concentrado el interés principal de la cooperación que estudiamos, con un poco más del $52 \%$ de todos los proyectos realizados en el período 1992-2003.

Respecto a los proyectos de las áreas humanitarias, el primer lugar lo ocupa salud, con 47 iniciativas. Luego están educación, con 30 (12,24\%); y las iniciativas asociadas a alimentación y población con 19 cada una $(15,52 \%)$.

Tabla 6. América Latina y el Caribe: Cooperación humanitaria de Japón (№ de proyectos ejecutados por sector).

\begin{tabular}{|l|r|r|r|r|r|r|r|}
\hline Proyectos (Categorías) & 1992 & 1994 & 1997 & 2000 & 2003 & Total & $(\%)$ \\
\hline Agua & 2 & 0 & 1 & 2 & 0 & 24 & 9,80 \\
\hline Aire & 0 & 0 & 0 & 0 & 0 & 1 & 0,41 \\
\hline Alimentación & 2 & 2 & 2 & 1 & 0 & 19 & 7,76 \\
\hline Becarios & 1 & 1 & 1 & 0 & 0 & 8 & 3,27 \\
\hline Comunicación & 0 & 1 & 0 & 0 & 0 & 2 & 0,82 \\
\hline Condiciones sanitarias & 0 & 0 & 0 & 0 & 0 & 1 & 0,41 \\
\hline Cultura & 1 & 1 & 1 & 1 & 0 & 10 & 4,08 \\
\hline Educación & 2 & 1 & 1 & 3 & 2 & 30 & 12,24 \\
\hline Emergencia & 3 & 1 & 1 & 1 & 0 & 16 & 6,53 \\
\hline Medioambiente & 0 & 2 & 0 & 4 & 2 & 17 & 6,94 \\
\hline Paz & 0 & 0 & 0 & 0 & 0 & 1 & 0,41 \\
\hline Población & 0 & 0 & 1 & 1 & 7 & 19 & 7,76 \\
\hline Salud & 4 & 2 & 2 & 4 & 7 & 47 & 19,18 \\
\hline Seguridad pública & 0 & 0 & 0 & 0 & 0 & 1 & 0,41 \\
\hline Suministro equipos & 1 & 2 & 2 & 2 & 1 & 17 & 6,94 \\
\hline Turismo & 0 & 1 & 1 & 0 & 0 & 5 & 2,04 \\
\hline Voluntarios & 1 & 1 & 1 & 0 & 0 & 8 & 3,27 \\
\hline Otros & 0 & 3 & 4 & 1 & 0 & 19 & 7,76 \\
\hline Total & 17 & 18 & 18 & 20 & 19 & 245 & 100,00 \\
\hline
\end{tabular}

Fuente: Elaboración propia, sobre la base de información oficial de las páginas web de JICA en cada país indicado.

Notas: a) La columna de totales ha sido complementada con los datos de El Salvador, país que sólo exhibe las cifras totales (no desagregadas por año) del período 1992-2003. Por esta razón, la fila de totales por año es diferente a la tabla por subregiones; b) La serie completa puede verse en Ross (2008).

Como cuestiones complementarias, se encuentra la cooperación relacionada con el envío de becarios $(3,27 \%)$, proyectos de cultura $(4,08 \%)$, 
suministro de equipos $(6,94 \%)$, iniciativas para enfrentar las emergencia, especialmente en Centroamérica (6,53\%) y envío de voluntarios $(3,27 \%)$.

\section{JAPÓN: COOPERACIÓN Y PODER HACIA AMÉRICA} LATINA, 1992-2003

Una parte sustantiva del debate académico especializado ${ }^{12}$ en los temas de cooperación japonesa hacia América Latina ha coincidido en aseverar que ésta es el principal instrumento de la política exterior nipona y que mediante ella se habría sustituido aquel otro poder, derivado de la fuerza, al que Japón renunció luego del término de la Segunda Guerra Mundial, y que se ha denominado "doctrina Yoshida".

En este contexto, se ha insinuado que la cooperación japonesa es una vía político-financiera para "perforar soberanías" económicas mediante la seducción (soft power) de la ayuda (humanitaria y para el desarrollo), con el propósito de mejorar la posición de Japón para desarrollar su comercio y para realizar proyectos de inversión directa.

Sin embargo, esta afirmación que aparece como bastante poderosa, no se encuentra suficientemente demostrada y es en ese campo específico donde entraremos a continuación.

Como hipótesis para esta parte se afirma que por el contrario de lo que sostiene la mayoría de la bibliografía, en relación a que sí existe concentración de la cooperación en aquellos sectores y subsectores económicos donde se concentra el comercio y las inversiones directas, la evidencia empírica no permite sostener que sí exista dicha correlación entre comercio, inversión directa y cooperación.

Tal contradicción abre un campo para una nueva indagación, más específica: por país, por sector y subsector económico y por proyectos de cooperación específicos.

Primero, se examinará la distribución regional del comercio, inversiones y cooperación japonesa por separado, para luego abordar la cooperación en correlación con el comercio y las inversiones.

\footnotetext{
${ }^{12}$ Aunque ellos aparecen en la sección de bibliografía de este trabajo, debe señalarse que el autor principal de este planteamiento es el profesor David Arase.
} 


\subsection{Distribución regional del comercio, las inversiones y la cooperación japonesa}

El análisis general del comercio entre Japón y América Latina permite advertir que éste ha estado centrado en América del Sur, aunque con una participación creciente de México, cuyo volumen de transacciones casi equiparó a la subregión mencionada en el año 2003.

Resulta muy interesante advertir que, aparentemente, la crisis mexicana denominada como efecto Tequila (1994), así como la Crisis Asiática (1997), no fueron puntos de inflexión, dentro de la tendencia general que describe la gráfica siguiente. Es posible plantear preliminarmente que esta tendencia más bien responde al ingreso de México al NAFTA y a las consecuencias comerciales derivadas de ese acuerdo, tales como el interés de las empresas japonesas por hacer transformación industrial (maquila) en México para acceder al mercado de los Estados Unidos.

Centroamérica y el Caribe, correlativamente al tamaño de sus propias economías, representa un porcentaje muy bajo del comercio japonés en América Latina.

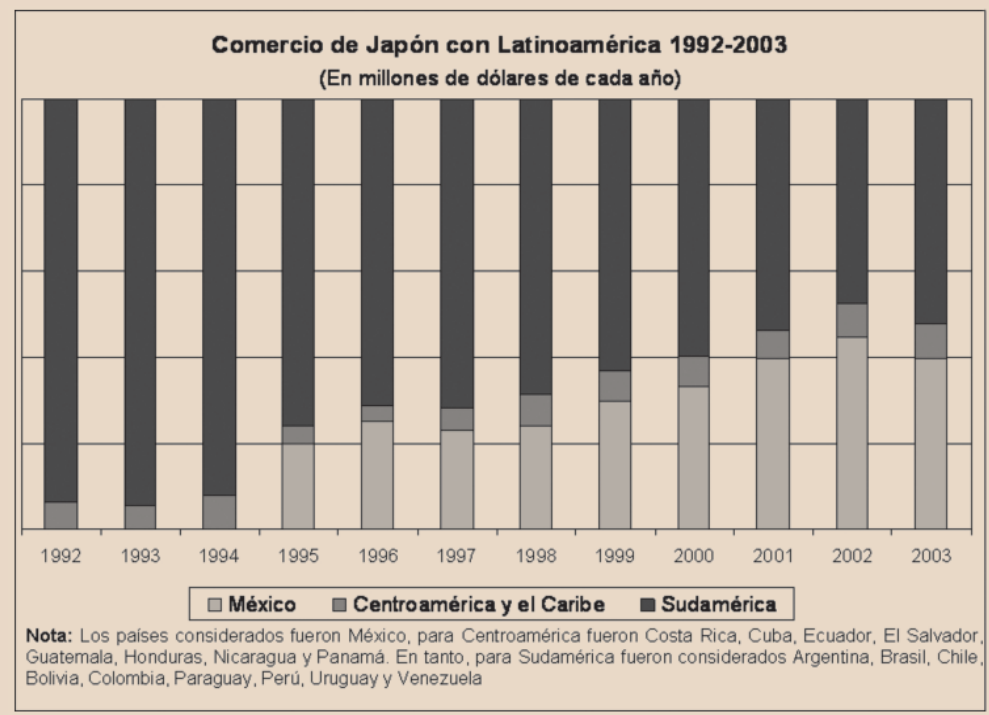

Gráfico 1. 
Por su parte, las inversiones directas de Japón en América Latina ofrecen un panorama muy interesante. Desde luego, destaca el lugar relevante de Centroamérica y el Caribe en la captación de estos capitales, los que desbordan el tamaño de sus propias economías. En el análisis comparativo estricto, es posible constatar que exceptuando los años 1997, 2001 y 2003, en todos los años de la serie esta subregión ocupa el segundo lugar en la captación de estos capitales. Esto abre un espacio muy interesante para una indagación más pormenorizada que aquí no alcanzamos a hacer, pero en la que debe profundizarse.

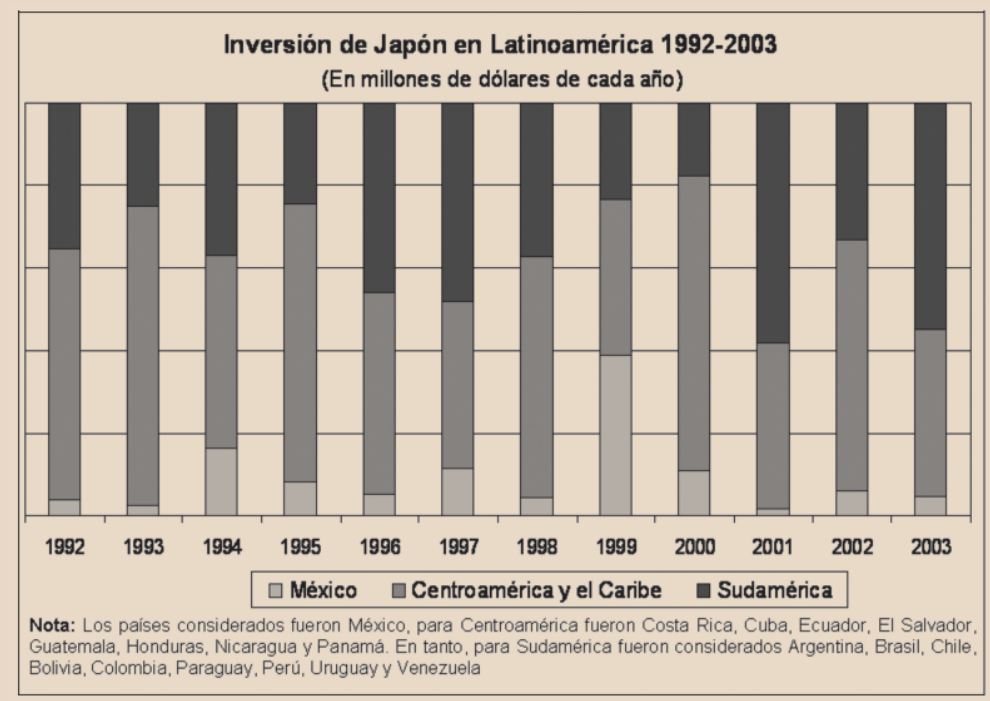

Gráfico 2.

No obstante tratarse de un solo país, las inversiones en México son muy inferiores que las realizadas en las otras 2 áreas de análisis, considerando el tamaño de la economía azteca y su vínculo privilegiado con el mercado de los Estados Unidos. Para las cifras de inversiones en México, es posible advertir que 1994 y 1999 son años "peak", cuya asociación con las crisis de Tequila y Asiática no resultan automáticas, dada la lógica de largo plazo involucrada en la toma de decisiones en el ámbito de inversiones extranjeras directas y debido a que ellas no deben ser evaluadas como flujos. Por cierto, una crisis en México y una crisis en Japón son datos relevantes en la interpretación asociada a la tendencia. 


\subsection{La cooperación japonesa en correlación con el comercio y las inversiones}

Para el caso de toda la región de América Latina y el Caribe, el comercio bilateral exhibe una fase ascendente en el lapso 1992-95 y dos ciclos muy tenues, con dos años de "peak" en 1997 y 2001, que siendo años de crisis aparecen seguidos por caídas muy suaves.

Respecto de la inversión, se advierte una tendencia muy errática con unos pequeños peak en 1994, en 1999 y en 2001. Todo el período con una tendencia de variaciones suaves y con volúmenes de capitales muy bajos.

En cuanto a la cooperación, se observa un solo ciclo, con un año de peak en 1994, tras el cual los montos descendieron para no volver a recuperar el nivel exhibido entre el "peak" y el lapso inmediatamente posterior (hasta 1996).

Tal como se observa en la siguiente gráfica, la correlación entre las tres variables es muy baja y sólo se aprecia un subperíodo de correlación inversamente proporcional en el lapso 1994-96, para las variables inversión y cooperación, lo que más bien contradice la tesis central de los autores que han analizado la cuestión de la cooperación japonesa en América Latina.

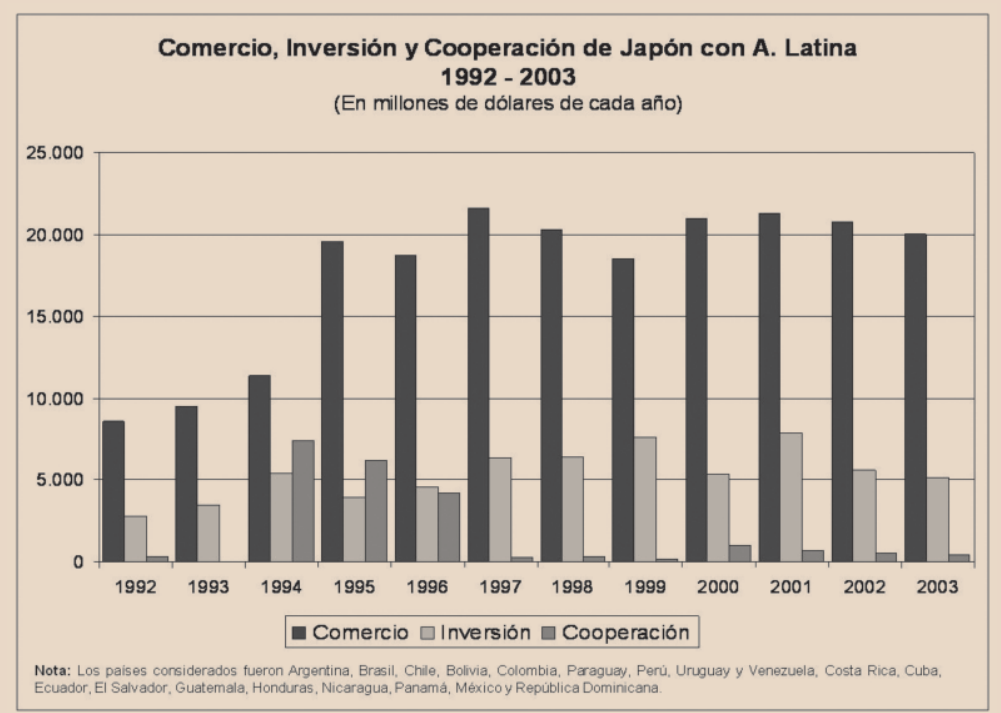

Gráfico 3. 
Para el caso de México, único país de América Latina en América del Norte, la situación es relativamente similar a la referida a la región en su conjunto.

El comercio bilateral exhibe un solo ciclo con claridad entre los años 1995 y 2003, mediante una tendencia suave con un año "peak" en 2002.

En la inversión se advierte una tendencia muy errática con dos años de "peak" muy bajos en 1994 y en 1999.

En consecuencia, en este caso particular tampoco se observa correlación entre las tres variables en análisis.

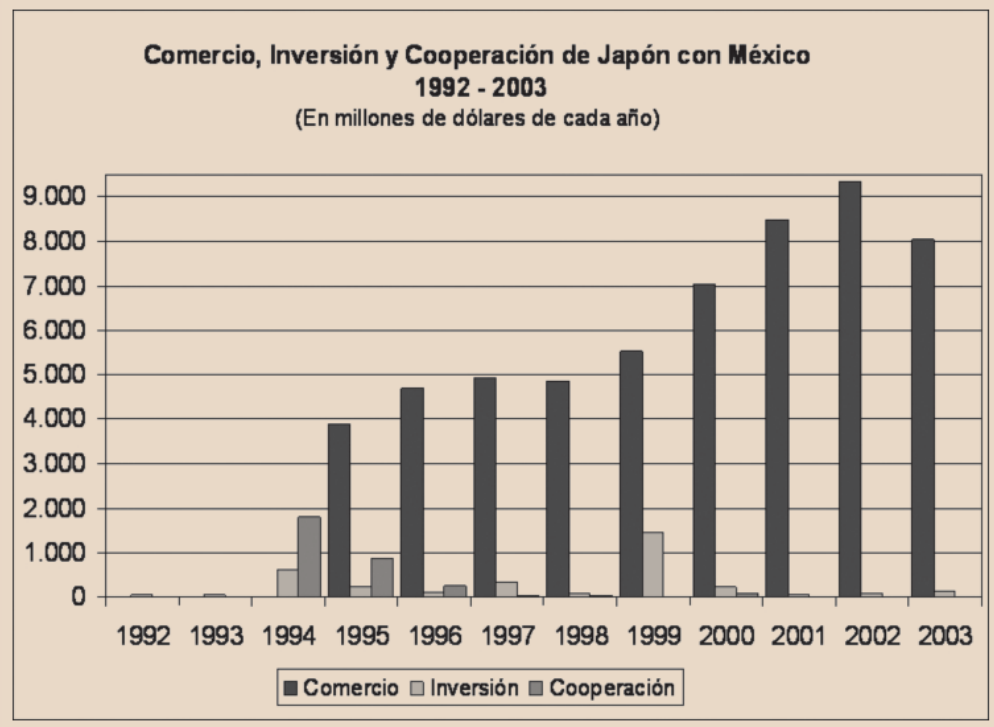

Gráfico 4.

Para el caso de Centroamérica y el Caribe, la situación se observa más compleja y variada, especialmente en lo referido a las inversiones directas.

Respecto del comercio se observan 3 ciclos (1992-96, 1996-99 y 19992003). El año "peak" del primer ciclo fue 1994 (efecto Tequila), el "peak" del segundo ciclo es 1998 (crisis Asiática) y el tercer ciclo es una tendencia de recuperación bastante suave, que recupera el nivel de pre Crisis Asiática en 2002.

La inversión japonesa en Centroamérica y el Caribe alcanzó niveles su- 
periores a los del comercio, especialmente para el subperíodo 1992-97. Sólo se vio superada por la cooperación en los años 1995-96 y por el comercio en los tramos 1997-98 y 2000-03.

Desde el punto de vista de la tendencia de la inversión, se aprecian dos ciclos. El primero entre los años 1992 y 1996, con un peak en el bienio 1994-95. El segundo ciclo, menos nítido, para el período 1998-2002, con un peak en el lapso 1999-2000. Como se planteó anteriormente, los montos muy elevados de la inversión japonesa en esta subregión deben ser sometidos a un examen más pormenorizado, dado que no guardan una relación muy directa ni con el nivel del comercio bilateral ni con el potencial de estas economías.

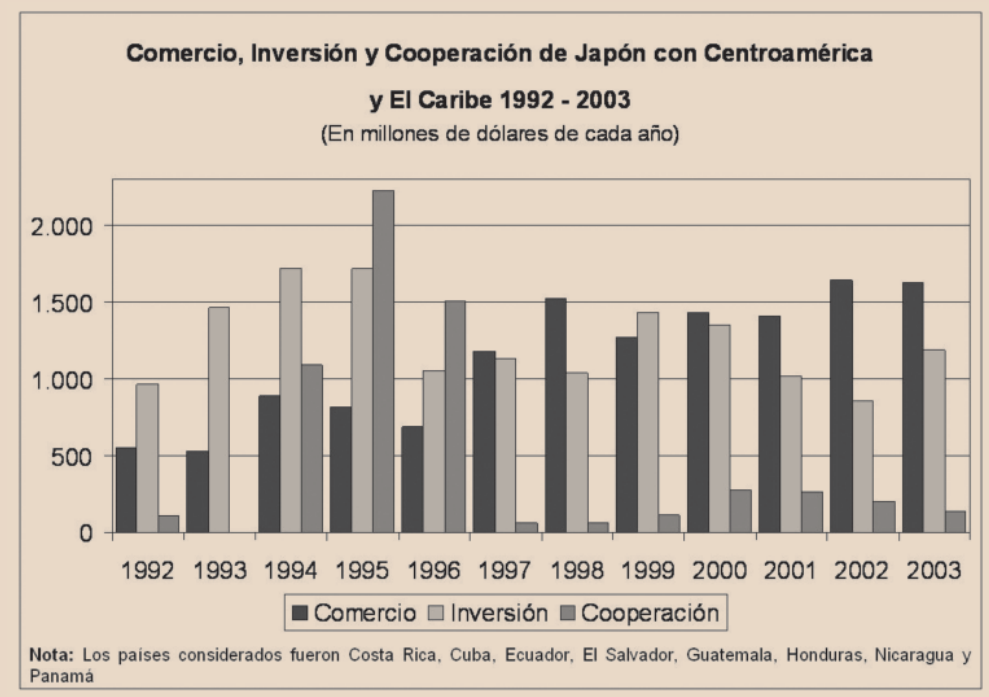

Gráfico 5.

Respecto de la cooperación misma, se advierten dos ciclos en dos niveles muy disímiles. El primero cubre el período 1992-97, con un peak que en 1995 supera excepcionalmente a la inversión y al comercio. El segundo ciclo cubre el período 1997-2003, con un peak en el año 2000. En estos años, la cooperación comprometida para el lapso 1995-96 fue excepcionalmente alta, centrada en Honduras y Guatemala, que para el período completo ob- 
tuvieron 83 y 39 proyectos respectivamente. En el caso de Honduras, tiene relación con el paso de dos huracanes, Luis y Opal ${ }^{13}$, en el año 1995. En el caso de Guatemala, la ayuda se ocupó de reforzar el proceso democrático debido a que los rebeldes declararon un cese el fuego, dando una tregua a la violencia registrada desde el año 1960. En 1996 Álvaro Aarhus llega a la presidencia, realiza una purga dentro del ejército y firma un acuerdo de paz con los rebeldes, terminando así 36 años de guerra civil.

Miradas las tres variables en conjunto, se puede aseverar que a contar de 1996 se observa una correlación entre comercio e inversión, especialmente en el lapso 1997-2000, pero esto no involucra a la cooperación en la medida que la bibliografía aludida anteriormente lo había señalado.

Respecto de Sudamérica, la situación parece bastante nítida, donde el grueso del vínculo estuvo centrado en el comercio, mientras que las inversiones y la cooperación han ocupado un lugar muy secundario.

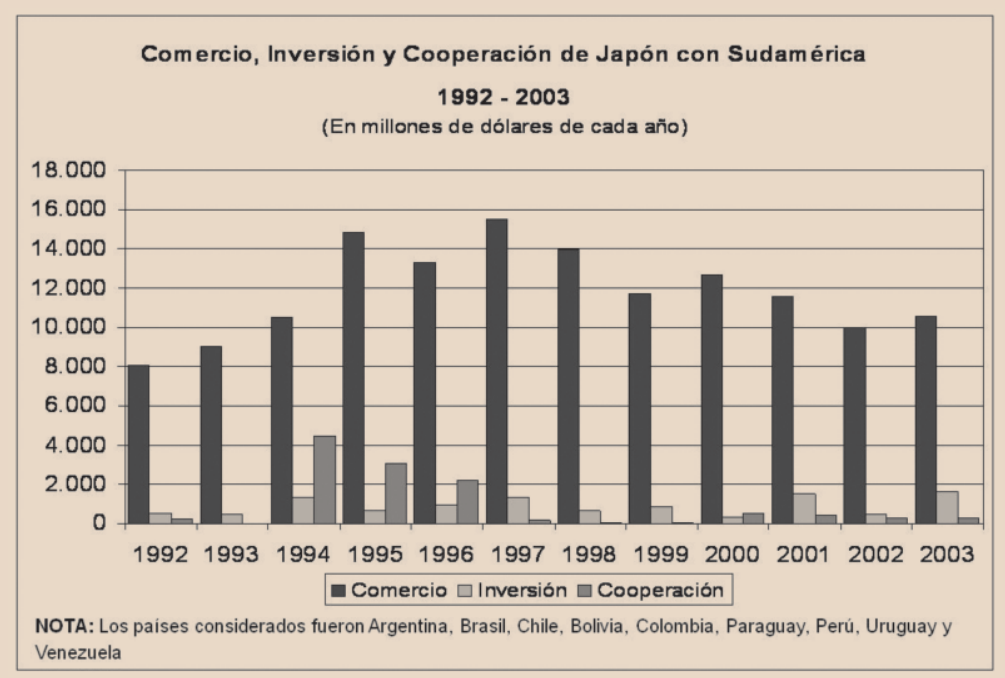

Gráfico 6.

${ }^{13}$ Ver: http://200.3.224.183/SMN/index.php?option=com_content\&task=view\&id=132\&Ite mid=232 y http://www.crid.or.cr/crid/CD_Huracanes/DocsIndex.html (ambas consultadas por última vez el 07 de abril de 2008). 
El comercio estuvo sujeto a la tendencia general de la economía, con una inflexión en el año 1997 y asociada a la Crisis Asiática.

Por su parte, la inversión exhibió un ciclo muy errático y alcanzó promedios muy bajos.

La cooperación, en tanto, estuvo sujeta a un ciclo único. Comenzó muy bajo (1992), con un peak en 1994 y con una fase decreciente hasta 1997, a contar de cuyo año el monto anual se mantuvo en un bajo nivel.

Siguiendo la tendencia general, en el caso de Sudamérica no se aprecia correlación entre las tres variables. No es posible determinar que la cooperación esté sujeta a los intereses de Japón en los ámbitos del comercio o de la inversión en América Latina.

\section{CONCLUSIÓN}

En síntesis, en este artículo se ha planteado como hipótesis general que las relaciones entre ambas regiones ha estado caracterizada por una combinación entre cooperación y negocios, pero cuyo detalle no permite aseverar ni que haya correlación plena entre los intereses de los negocios con los de la cooperación, ni que sea posible afirmar que la cooperación, como un verdadero "soft power" sea restituida con compensaciones económicas.

Del mismo modo, la inexistencia actual de una base empírica para refutar la tesis de Arase en el caso de América Latina y el Caribe, no permite afirmar de manera tajante que dichos intereses no existan y no operen en alguna medida.

Con todo, el contexto general en el que estas relaciones se han desarrollado es un escenario muy propicio para suponer que sí se han correlacionado las variables de cooperación, negocios e intereses políticos. Hasta aquí, sin embargo, no podemos incluir la última variable con suficiente propiedad.

Como se planteó en las páginas anteriores, el fenómeno analizado estuvo sujeto a cuatro cuestiones centrales:

Primero, al tipo de restricción a la que estuvo sometido Japón en la post Segunda Guerra Mundial. En esos años, Europa, Japón y una parte de América Latina quedaron bajo la influencia hegemónica de los Estados Unidos. En ese escenario, se optó por buscar la nueva razón de ser del país en "el sistema de libre comercio, centrado alrededor de Estados Unidos y Gran Bretaña", donde pretendía hallar el espacio necesario para que Japón fuera nuevamente aceptado en la sociedad internacional. 
Esta estrategia, conocida como "doctrina Yoshida", derivó en que Japón operara con una política exterior reducida a los ámbitos de la "baja política", centrada en los intereses económicos del país asiático.

Segundo, después de años de una política internacional de bajo perfil, en un contexto nacional en donde los debates sobre política de seguridad eran casi inexistentes, nos encontramos con que se estaría formando un amplio consenso para que Japón imponga su interés nacional más poderosamente. Se puede ver que en esta tensión existe una emergente visión estratégica -un realismo reticente- que se está constituyendo por tres factores: en primer lugar, por la combinación de información del cambio de escenario internacional de Japón, en segundo lugar por la inseguridad acerca de las fuentes del poder nacional y en tercer lugar, por las aspiraciones relacionadas con la identidad nacional, y que van más allá del legado de la Segunda Guerra Mundial.

Tercero, desde el punto de vista de la política exterior, la AOD se fue transformando en una fuente de prestigio y legitimidad internacional, tanto por ser una manera de "comprar poder" (Arase, 1995), como por constituirse en una forma de ejercer un tipo muy atractivo de "soft power".

Cuarto, en oposición a lo que sostiene la mayoría de los autores (muchos de ellos citados en este trabajo), en relación a que sí existe concentración de la cooperación en aquellos sectores y subsectores económicos donde se concentra el comercio y las inversiones directas, la evidencia empírica no permite sostener que sí exista dicha correlación entre comercio, inversión directa y cooperación.

Tal contradicción abre un campo para una nueva indagación, más específica: por país, por sector y subsector económico, y por proyectos de cooperación específicos. Todo esto, además, conectado al ejercicio de los intereses políticos de Japón en América Latina y a la reacción de los países de esta región en relación a dicha influencia. 


\section{Anexo: Tablas}

1. Comercio de Japón con Latinoamérica 1992-2003 (en millones de dólares de cada año).

\begin{tabular}{|l|c|c|c|c|c|c|}
\hline País/Región & 1992 & 1993 & 1994 & 1995 & 1996 & 1997 \\
\hline México & s.i. & s.i. & s.i. & $3.896,50$ & $4.684,20$ & $4.915,60$ \\
\hline Centroamérica & 549,8 & 532,4 & 889,1 & 810,4 & 689,4 & $1.177,10$ \\
\hline Sudamérica & $8.037,10$ & $9.005,00$ & $10.519,60$ & $14.854,10$ & $13.349,80$ & $15.522,50$ \\
\hline País/Región & 1998 & 1999 & 2000 & 2001 & 2002 & 2003 \\
\hline México & $4.850,50$ & $5.524,20$ & $7.048,30$ & $8.471,90$ & $9.337,50$ & $8.030,20$ \\
\hline Centroamérica & $1.523,80$ & $1.269,10$ & $1.434,70$ & $1.409,90$ & $1.643,70$ & $1.631,30$ \\
\hline Sudamérica & $13.948,40$ & $11.735,10$ & $12.702,90$ & $11.531,20$ & $9.977,10$ & $10.573,60$ \\
\hline
\end{tabular}

Fuente: Elaboración propia, sobre la base de la información indicada en Fuentes de este trabajo.

Nota 1: Los países considerados en Centroamérica y el Caribe fueron Costa Rica, Cuba, Ecuador, El Salvador, Guatemala, Honduras, Nicaragua y Panamá.

Nota 2: Los países considerados en Sudamérica fueron Argentina, Brasil, Chile, Bolivia, Colombia, Paraguay, Perú, Uruguay y Venezuela.

2. Inversión de Japón en Latinoamérica 1992- 2003 (en millones de dólares de cada año).

\begin{tabular}{|l|c|c|c|c|c|c|}
\hline País/Región & 1992 & 1993 & 1994 & 1995 & 1996 & 1997 \\
\hline México & 61,66 & 55,08 & 607,17 & 214,62 & 116,97 & 322,5 \\
\hline Centroamérica & 965,29 & $1.464,69$ & $1.718,83$ & $1.715,89$ & $1.051,81$ & $1.132,45$ \\
\hline Sudamérica & 554,98 & 507,5 & $1.358,48$ & 622,61 & 988,76 & $1.340,88$ \\
\hline País/Región & 1998 & 1999 & 2000 & 2001 & 2002 & 2003 \\
\hline México & 81,05 & $1.464,34$ & 212,28 & 47,4 & 82,57 & 136,43 \\
\hline Centroamérica & $1.038,31$ & $1.435,14$ & $1.352,10$ & $1.014,14$ & 861,79 & $1.187,29$ \\
\hline Sudamérica & 662,13 & 873,3 & 334,1 & $1.484,84$ & 469,78 & $1.606,08$ \\
\hline
\end{tabular}

Fuente: Elaboración propia, sobre la base de la información indicada en Fuentes de este trabajo.

Nota: Los países considerados fueron Argentina, Brasil, Chile, Bolivia, Colombia, Paraguay, Perú, Uruguay y Venezuela, Costa Rica, Cuba, Ecuador, El Salvador, Guatemala, Honduras, Nicaragua, Panamá, México y República Dominicana. 
3. Comercio, Inversión y Cooperación de Japón con A. Latina 1992-2003 (en millones de dólares de cada año).

\begin{tabular}{|l|c|c|c|c|c|r|}
\hline País/Región & 1992 & 1993 & 1994 & 1995 & 1996 & \multicolumn{1}{c|}{1997} \\
\hline México & $8.586,90$ & $9.537,40$ & $11.408,70$ & $19.561,00$ & $18.723,40$ & $21.615,20$ \\
\hline Centroamérica & $2.787,57$ & $3.511,83$ & $5.428,97$ & $3.974,71$ & $4.578,27$ & $6.380,27$ \\
\hline Sudamérica & 326,66 & 0 & $7.404,32$ & $6.207,56$ & $4.225,32$ & 254,5 \\
\hline País/Región & 1998 & 1999 & 2000 & 2001 & 2002 & \multicolumn{1}{c|}{2003} \\
\hline México & $20.322,70$ & $18.528,40$ & $20.988,10$ & $21.273,00$ & $20.783,60$ & $20.036,00$ \\
\hline Centroamérica & $6.383,52$ & $7.621,66$ & $5.388,09$ & $7.889,19$ & $5.615,68$ & $5.136,00$ \\
\hline Sudamérica & 333,04 & 206,58 & 962,31 & 725,96 & 518,57 & 461,45 \\
\hline
\end{tabular}

Fuente: Elaboración propia, sobre la base de la información indicada en Fuentes de este trabajo.

Nota: Los países considerados fueron Argentina, Brasil, Chile, Bolivia, Colombia, Paraguay, Perú, Uruguay y Venezuela, Costa Rica, Cuba, Ecuador, El Salvador, Guatemala, Honduras, Nicaragua, Panamá, México y República Dominicana.

4. Comercio, Inversión y Cooperación de Japón con México 1992-2003 (en millones de dólares de cada año).

\begin{tabular}{|l|c|c|c|c|c|c|}
\hline País/Región & 1992 & 1993 & 1994 & 1995 & 1996 & 1997 \\
\hline México & s.i. & s.i. & s.i. & $3.896,50$ & $4.684,20$ & $4.915,60$ \\
\hline Centroamérica & 61,66 & 55,08 & 607,17 & 214,62 & 116,97 & 322,5 \\
\hline Sudamérica & 0 & 0 & $1.801,05$ & 847,73 & 256,99 & 28,64 \\
\hline País/Región & 1998 & 1999 & 2000 & 2001 & 2002 & 2003 \\
\hline México & $4.850,50$ & $5.524,20$ & $7.048,30$ & $8.471,90$ & $9.337,50$ & $8.030,20$ \\
\hline Centroamérica & 81,05 & $1.464,34$ & 212,28 & 47,4 & 82,57 & 136,43 \\
\hline Sudamérica & 29,92 & 0 & 93,93 & $-10,98$ & $-11,49$ & 11,69 \\
\hline
\end{tabular}

Fuente: Elaboración propia, sobre la base de la información indicada en Fuentes de este trabajo.

5. Comercio, Inversión y Cooperación de Japón con Centroamérica y el Caribe 1992-2003 (en millones de dólares de cada año).

\begin{tabular}{|l|c|c|c|c|c|c|}
\hline País/Región & 1992 & 1993 & 1994 & 1995 & 1996 & 1997 \\
\hline México & 549,8 & 532,4 & 889,1 & 810,4 & 689,4 & $1.177,10$ \\
\hline Centroamérica & 965,29 & $1.464,69$ & $1.718,83$ & $1.715,89$ & $1.051,81$ & $1.132,45$ \\
\hline Sudamérica & 106,6 & 0 & $1.093,26$ & $2.224,88$ & $1.510,93$ & 62,33 \\
\hline País/Región & 1998 & 1999 & 2000 & 2001 & 2002 & 2003 \\
\hline México & $1.523,80$ & $1.269,10$ & $1.434,70$ & $1.409,90$ & $1.643,70$ & $1.631,30$ \\
\hline Centroamérica & $1.038,31$ & $1.435,14$ & $1.352,10$ & $1.014,14$ & 861,79 & $1.187,29$ \\
\hline Sudamérica & 62,95 & 115,58 & 277,86 & 259,05 & 205,18 & 132,77 \\
\hline
\end{tabular}

Fuente: Elaboración propia, sobre la base de la información indicada en Fuentes de este trabajo.

Nota: Los países considerados fueron Costa Rica, Cuba, Ecuador, El Salvador, Guatemala, Honduras, Nicaragua y Panamá. 
6. Comercio, Inversión y Cooperación de Japón con Sudamérica 1992-2003 (en millones de dólares de cada año).

\begin{tabular}{|l|r|r|r|r|r|r|}
\hline País/Región & \multicolumn{1}{c|}{1992} & \multicolumn{1}{c|}{1993} & \multicolumn{1}{c|}{1994} & \multicolumn{1}{c|}{1995} & \multicolumn{1}{c|}{1996} & \multicolumn{1}{c|}{1997} \\
\hline México & $8.037,10$ & $9.005,00$ & $10.519,60$ & $14.854,10$ & $13.349,80$ & $15.522,50$ \\
\hline Centroamérica & 554,98 & 507,5 & $1.358,48$ & 622,61 & 988,76 & $1.340,88$ \\
\hline Sudamérica & 219,05 & 0 & $4.462,66$ & $3.084,35$ & $2.211,61$ & 150,35 \\
\hline País/Región & 1998 & 1999 & 2000 & 2001 & 2002 & 2003 \\
\hline México & $13.948,40$ & $11.735,10$ & $12.702,90$ & $11.531,20$ & $9.977,10$ & $10.573,60$ \\
\hline Centroamérica & 662,13 & 873,3 & 334,1 & $1.484,84$ & 469,78 & $1.606,08$ \\
\hline Sudamérica & 59,48 & 65,84 & 545,37 & 427,07 & 273,36 & 276,01 \\
\hline
\end{tabular}

Fuente: Elaboración propia, sobre la base de la información indicada en Fuentes de este trabajo.

Nota: Los países considerados fueron Argentina, Brasil, Chile, Bolivia, Colombia, Paraguay, Perú, Uruguay y Venezuela.

Fuentes: Gráficos y Anexo de tablas

\section{Comercio}

Datos de ALADI para Venezuela, Perú, México, Ecuador, Cuba, Colombia y Bolivia, disponibles en la página web http://nt5000.aladi.org/sii/menupagsinternas/marcossii.htm (consultado en 02/05/2008).

Bancos centrales de Argentina, Brasil, Uruguay, Paraguay, Guatemala, Costa Rica, El Salvador, Honduras y Nicaragua.

Gobierno de Panamá: Sección de Análisis Económicos de Panamá.

Banco Central de Chile, "Indicadores de Comercio Exterior de Chile período 1960-2000".

Boletín mensual de la SOFOFA, Chile, período estudiado. www.sofofa.cl

\section{Cooperación}

JICA: 1992-1993, Annual Report; 1995-2000, Reporte Anual; 2001-2003: Annual Report (versión electrónica): http://www.jica.go.jp/english/resources/publications/annual/index.html (consultado en 04/02/2008)

Conversión a dólares utilizando datos del valor del yen de cada año de LVA Índices/Bloomberg.

\section{Inversión}

Japan External Trade Organization, JETRO, disponible en: http://www.jetro.go.jp/argentina/datos/inversion/pdf/odi_paisregion.pdf

Conversión a dólares utilizando datos del valor del yen de cada año de LVA Índices/Bloomberg. 


\section{REFERENCIAS}

Arase, D. (1995). Buying Power. The Political Economy of Japan's Foreign Aid. London: Lynne Rienner Publishers.

Castells, M. (2000). “¿Hacia la era del Pacífico? El fundamento multicultural de la interdependencia económica”, en La era de la información, economía, sociedad y cultura. Fin del Milenio, Vol. III, Siglo XXI editores, Segunda edición en español, pp. 235-341.

Fukushima, A. (1999). Japanese Foreign Policy. The Emerging Logic of Multiculturalism. London-United Kingdom: Macmillan Press.

Galbraith, J. K. (1985). La anatomía del poder. Barcelona: Plaza \& Janés.

Gilpin, R. (1981). War and Change in World Politics. Cambridge: Cambridge University Press.

Green, M. J. (2003). Japan's Reluctant Realism. Foreign Policy Challenges in an Era of Uncertain Power. New York: Palgrave.

Hagström, L. (2003). Enigmatic Power? Relational Power Analysis and Statecraft in Japan's China Policy. Stocholm: Stocholm University.

Hirabayashi, H. (1995). "El Programa Japonés de ayuda oficial al desarrollo", La toma del liderazgo en la Nueva Era", en Akio Hosono, La economía japonesa en una época en transición. Barcelona: Japan Echo INC, INTER-Edit, 19-38.

Hook, G. D. et al. (2001). Japan's International Relations. London: Routledge.

Horisaka, K. (1994). "Las relaciones económicas de Japón con América Latina", en Stallings, Barbara; Székely, Gabriel (comps.), Japón, los Estados Unidos y la América Latina. ¿Hacia una relación trilateral en el hemisferio occidental? México: Fondo de Cultura Económica, 61-87.

Hosono, A. (1995). "La cooperación económica y las relaciones entre Japón y los países latinoamericanos", en Akio Hosono, La economía japonesa en una época en transición. Barcelona: Japan Echo INC, INTER-Edit, 65-76.

Ikenberry, G. J. (2003). International Relations Theory and the Asia Pacific. New York: Columbia University Press.

Kikuchi, K. (1993). El origen del poder. Historia de una nación llamada Japón. Buenos Aires: Editorial Sudamericana.

Makoto, I. (2000). Entrevista. Look Japan, Vol. 11, № 129, dic., 2-11.

Masataka, K. (2000). Entrevista. Look Japan, Vol. 11, No 129, dic., 2-11.

Morgenthau, H. [1948] (1986). Politica entre naciones. La lucha por el poder y la paz. Buenos Aires: Grupo Editor Latinoamericano.

North, D. C. (1990). Institutions, Institutional Change and Economic Performance. New York-United States: Cambridge University Press.

Nye Jr., J. (2004). Soft Power. The Means to Success in World Politics. New York: Public Affairs.

Powaski, R. (1998). Cold War. The United States and the Soviet Union, 19171991. Oxford: Oxford University Press. 
Pyle, K. B. (1992). The Japanese Questions: power and purpose in a new era. Washington D. C.: American Enterprise Institute.

Ross, C. (2008). "La cooperación japonesa hacia América Latina, 1992-2003: Una aproximación cuantitativa”. Política y Estrategia No 110, 108-135.

Togo, K. (2005). Japan's Foreign Policy, 1945-2003. The Quest for a Proactive Policy. London: Brill. 